\title{
Vaginal Adenosis
}

National Cancer Institute

\section{Source}

National Cancer Institute. Vaginal Adenosis. NCI Thesaurus. Code C128063.

The presence of glandular structures in the vagina. 